\section{ECONOMICS}

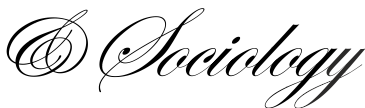

\title{
SOCIO-CULTURAL CAPITAL AS A CAUSE OF ECONOMIC AND INSTITUTIONAL CRISIS IN MONTENEGRO, SERBIA AND BOSNIA AND HERZEGOVINA
}

\author{
Milica Delibasic, \\ Mediterranean University, \\ Faculty of Business Studies, \\ Podgorica, Montenegro, \\ E-mail: 23.mildel@gmail.com
}

Received: December, 2017 1st Revision: March, 2018 Accepted: June, 2018

DOI: $10.14254 / 2071-$

789X.2018/11-4/14

JEL Classification: Z13
ABSTRACT. The subject of the article is to explain aspects and essential elements through which socio-cultural capital causes crisis effects (institutional, economic, and social) in the selected post-socialist countries of SouthEastern Europe - Montenegro (MNE), Serbia (SER), and Bosnia and Herzegovina $(\mathrm{B} \& \mathrm{H})$. The aim of this paper is to: a) model the structure and the role of socio-cultural capital; b) draw attention to the negative impacts of path dependence and new neoliberal culture; and c) suggest a new methodological criterion for the division of integral components of socio-cultural capital (inherited and imposed factors), which affected its decline in those countries. Its starting hypothesis is that legacy factors (conditionally: path dependency) and imposed factors (external and internal origin) in the observed transition countries have caused an erosion of many socio-cultural contents, which has led to a slowdown in economic, institutional, and social growth. Besides common methods of social sciences, the survey method has been used. The survey results show that socio-cultural capital suffered a decline, mostly due to a stagnation of bridging social capital and an increase in linking social capital, that is, due to a greater impact of imposed factors (generated in the new neoliberal culture) than inherited factors.

Keywords: socio-cultural capital, imposed impact factors, inherited impact factors, institutions, Montenegro, Serbia, Bosnia and Herzegovina.

\section{Introduction}

The inclusion of many structural components in the concept of socio-cultural capital has a major analytical and methodological meaning. Because all these components have a certain impact on the long-term reproduction of economic, institutional, and social crisis in the observed post-socialist transition countries (MNE, SER, and B\&H), and on the erosion of sociocultural capital (Draskovic et al., 2017) and all its individual forms (human, intellectual, social, symbolic, and ecological).

In recent years, some Montenegrin authors have studied the similarity of manifesting the important economic phenomena and categories (and also socio-cultural capital) in the SEE 
countries (Delibasic, 2016; Lakic \& Draskovic, 2015; Draskovic et al., 2016, 2017; Andrushkiv et al., 2011). They have empirically and theoretically proved the great dependence and low level of socio-cultural capital (as dependent variable) of the two braking factors (the quasiinstitutional monopoly of neoliberal type and the low rate of institutional change at all levels as independent variables). In this paper we have supplemented the number of independent variables (Figure 1) with: a) a great reduction in the level of education in the transition period, b) a dominant impact of alternative institutions, and c) an impact of other social factors.

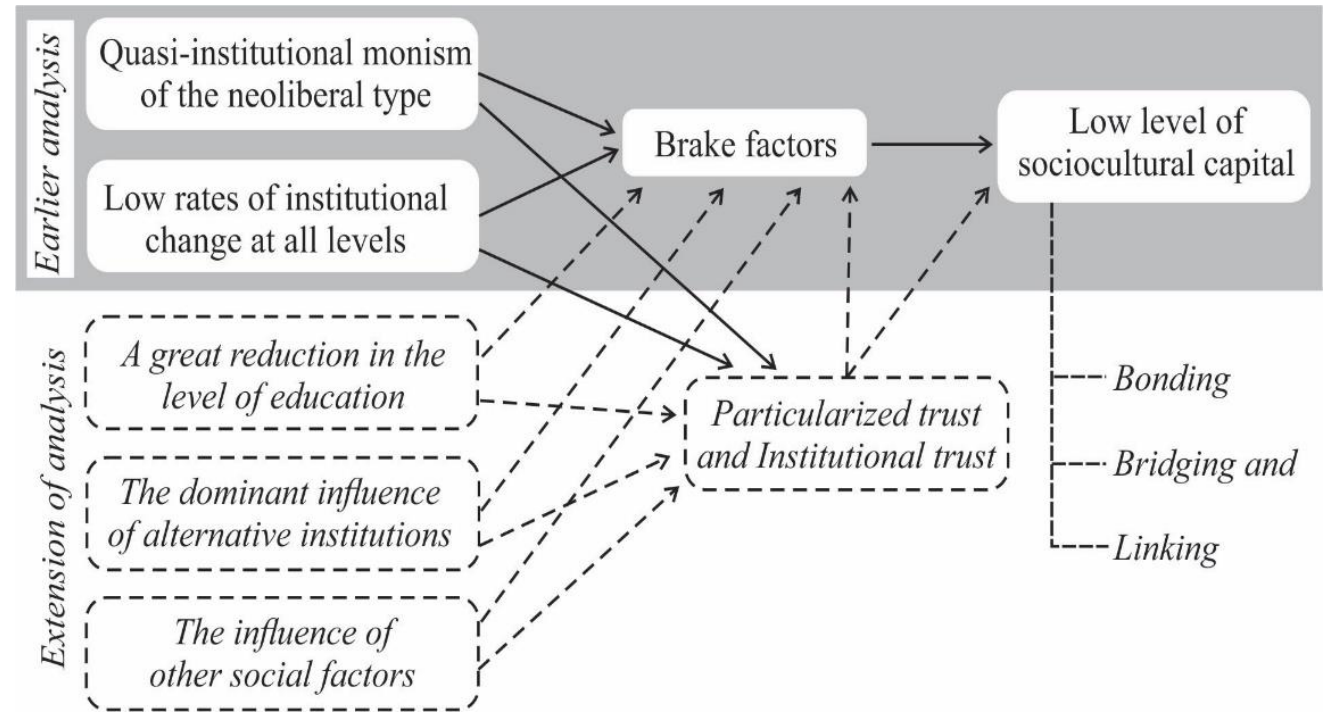

Figure 1. Old and new approach to the research of socio-cultural capital in the MNE, SER, and $\mathrm{B} \& \mathrm{H}$

In this article, survey was conducted according to different methodological criteria. Namely, all impact factors were simply divided into two basic groups: inherited and imposed. We opted for such a division because many impact factors (e.g. institutional), in various forms and ways of expression, have participated in both groups. This division allows to view the main impact factors in more detail and precise, and hence to better understand their real "contribution" to the dynamics of socio-cultural capital during three decades of post-socialist transition. In other words, this division allows to notice the following:

- drastic change in the dynamics of some inherited factors (e.g. the quality of higher education, social security, etc.) impacted by imposed factors,

- stagnation and prolonged action of some factors (e.g. the cult of personality, violence, etc.), and

- emergence of new impact factors (combat operations, alternative institutions, quasi-neoliberal ideology, deficit of the rule of law, etc.).

In the inherited impact factors on socio-cultural capital, we have included the most important: almost complete control by the privileged bureaucratic-party nomenclature (Delibasic, 2015), ruined socialist institutions (Jovovic, Draskovic \& Jovovic, 2017), the cult of personality (Draskovic, 2018), quality education, relatively high level of culture and social cohesion, a high level of social security, etc.

In the imposed impact factors on socio-cultural capital, we have included: warfare, which caused forced migrations (see Appadurai, 1996, p. 10; Butnaru et al., 2018), globalization, geopolitics and geoeconomics, monistic quasi-neoliberal ideology and culture (Vranceanu \& Iorgulescu, 2016), alternative institutions (Draskovic, Bauk \& Delibasic, 2016; 
Draskovic, Bauk, Streimikiene \& Draskovic 2017), an increase in opportunistic behavior, social pathology and violence (Draskovic, Popov \& Peleckis, 2017), a collapse of education system, deficiency in the rule of law, and antagonism of social subsystems (political, economic, cultural, ethical, social, motivational, technological, etc.).

\section{Literature review}

There are many approaches to studying socio-cultural capital. Some authors interpret it separately (as a cultural and social capital), and some interpret it as a whole. However, the fact is that all theoretical approaches indicate that social and cultural factors are considered the basis of institutional development, behavior of economic subjects and social growth. Thus, for example, T. Parsons (1977) has emphasized that "the cultural subsystem creates norms, values, rules, statuses, and services that are institutionalized within a social system". Culture is realized in social processes and institutions, which include, among others, the institutions of domination and political power, through various forms of intangible capital, which can affect transfer into financial resources. P. Bourdieu (1972, p. 49) argues that cultural values are passed on to generations and widen the possibilities of social mobility of the people. In addition, he (1986) correctly noted that the accumulation and use of cultural capital depends on the adoption and use of certain social norms in everyday practice (traditional, modernist, innovative, etc.). Explaining the complex interactions between formal and informal constraints in everyday social practices, D. North (1990) has pointed to the great role of cultural heritage, which determines the sustainability of many informal constraints and, consequently, institutional changes. In addition, it is about a "characteristic relationship structure between actors" (Coleman, 1988), a specific "social glue" (Paldam, 2000) and a phenomenon that has a social nature (not an individual nature - Portes, 1998). Refering to the aforementioned opinions, the World Bank (1999) also emphasizes the structural component: "Social capital refers to the institutions, relationships, and norms that shape the quality and quantity of a society's social interactions... Social capital is not just the sum of the institutions which underpin a society - it is the glue that holds them together". It is characterized by synergy, or a set of networked contacts of people, held together by institutions and society (Figure 2).

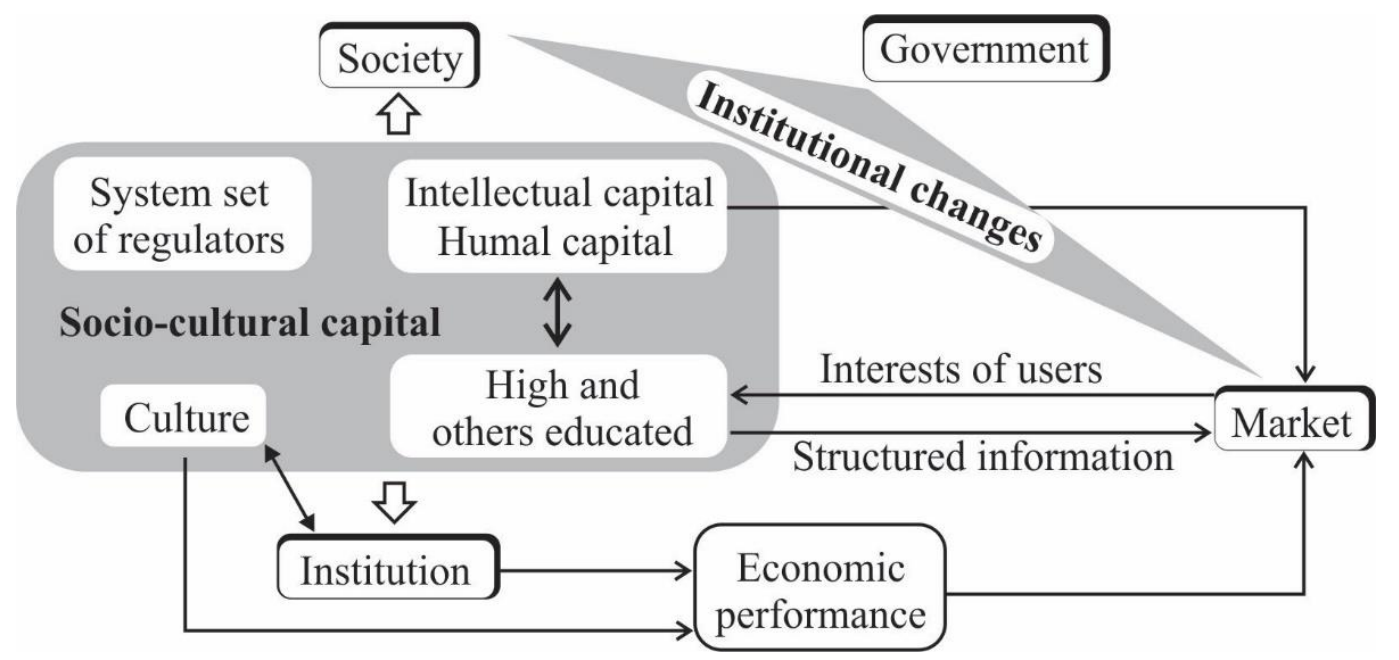

Figure 2. Structure and role of socio-cultural capital

P. Sorokin (1992, pp. 190-193) also considers that society, culture, and personality are an integral whole. Similar opinion is represented by B. Yerznkyan, L. Gassner \& A. Kara (2017). They support the attitude of D. North (1990, pp. 36-37) that informal institutions are "a 
part of the heritage that we call culture", and they conclude: "ability of two closely related phenomena, namely culture and institutions (especially the informal ones, such as codes of conduct, norms of behavior, and conventions), to impact economic performance". Furthermore, they correctly state that culture and institutions are closely linked towards the positive effects on economic performance.

G. Becker (1991), who defined the concept of human capital as a set of knowledge and skills (intellectual and creative potential), made a major contribution to the study of sociocultural capital. He explained how people get them in the course of education at a certain cost, which in time can bring benefits to employees and their employers. In addition to knowledge and education, socio-cultural capital includes a systemic set of regulatory ways of integrating and identifying, developing, organizing, motivating, communicating, mobilizing, linking, etc. Those are abilities to organize and link the interests of individual and collective subjects in society. This also includes (in addition to knowledge and investments in knowledge), the following intangible social resources: morality, ideology, culture, religion, the form of political regime, authority and trust in the government, historical continuity of institutional changes, social ties, etc.

D. Acemoglu et al. (2003) discuss the socio-cultural capital through the prism of social and economic growth. They consider it to be a set of informal institutions and social habits, which, under the influence of the existing government (reforms, political measures, privileges and priorities, etc.), can turn into developmental barriers or competitive advantages. Although politics always dominate the economy (to a greater or lesser extent), in a real life both of them absorb socio-cultural capital, that is, concrete ethical, cultural, and civilizational values. With it, a society establishes a certain order, which represents a social consensus, whose quality determines the level of organizational, economic, and institutional efficiency, as well as the path of development.

All these theoretical considerations indicate a complex and multidimensional resource category (in general observation of capital as an asset in function), in which many complicated relationships between participants of social actions (interactions) are converted, and which are generally responsible, reliable, and confidential. In other words, it is a logical construct (synthesis), because in a real life it culturally and socially acts as complementary phenomena (of reality), having similar directions of influence and principles in society, which are difficult to distinguish. Without the desire to explain terminological differences that exist in literature, socio-cultural capital is generally regarded as a synergistic resource, composed of values, perceptions, preferences, and real lives of people, observed in individual and group behavior. It is implemented through social networks, social norms of behavior of certain groups, mutual support and cooperation, whose goal is the realization of mutual benefits, which can be expressed as profit or optimization of social positions. Hence, always must be borne in mind that socio-cultural capital is a mediator in the system of mutual social activities, because it, like all other institutions, represents and conditiones these facts (North, 1990, p. 17, Hodgson, 2007).

\section{Negative impacts of path dependence and new neoliberal culture}

Certain negative socialist (previous) experiences of motivating people have not been eliminated. On the contrary, economic reductionism has generated new problems that have been generated in the fields of employment, general and higher education, social consensus and security, mentality and, in particular, alternative institutions. The latter have strengthened and constantly slowed down or even blocked institutional changes. Regarding the attitude towards the people, the new authorities turned out to be very similar to the former authorities, in a political sense. Political power and the cult of personality have continued to dominate society, 
thus limiting freedom of choice and freedom in general. Inherited socialist institutions (legal, organizational, economic, and political) have not been transformed in accordance with the needs of the proclaimed market economy as a monistic institution. Under the influence of a retrograde neoliberal doctrine (and its quasi-institutional manifestation in practice), there has been a recombination of inherited institutions with newly formed experimental institutions. A new „neoliberal“ (market) culture has been created. F. Fukuyama (1992) wrongly and paradoxically concluded that the beginning of this new culture meant ,the end of history". It was completely contrary to the previous Christian culture. It has resulted in devastating consequences, because instead of some market segments (not to mention an illusion of integral market) dominated by substitutes and imitations of the market. There was a sharp decline in production, employment, living standard, and all economic indicators, as well as the impoverishment and stratification of the people. All this has caused the erosion of institutional component of socio-cultural capital, which implies an accumulated trust. It is the product of moral norms and values in society. Thereby, we do not think that the level of trust in a particular society corresponds to the results of political elections (due to manipulation, voter turnout, etc.). On the contrary. Clearly, the paradox of distrust among the people towards the ones in power significantly and negatively affects the quality of socio-cultural capital and the efficient institutional functioning. In addition, a dangerous phenomenon of growing alienation from the power and the people has also been activated, having negative impact on the quality of sociocultural capital.

Most authors in the socio-cultural capital structure consider the presence of privileges (more or less), which significantly determine and degenerate its quality. These privileges are the result of a certain power nomenclature ideology. In the case of MNE, SER, and B\&H, there is a dominant influence of neoliberal ideology, which was based on the society westernization, interests and consumerism of non-market enriched elites, non-market privileges, negative selection of personnel, etc. Bearing in mind that privileges directly affect the reduction of social motivation, it becomes clear how socio-cultural capital has been degraded under the influence of these factors. Its degradation had a reverse negative impact and contributed to the blockade of the institutional development and other changes.

Using economic terminology, every analysis of real social and economic reality in MNE, SER and B\&H consideres the existence of many socio-pathological phenomena and opportunistic behavior, which significantly increase transaction costs in the economy and society, reducing economic choices and disabling the creation of optimal conditions for economic growth and economic development. In this sense, the research of socio-cultural capital becomes the major carrier (source), and therefore the cause of the stated negativity.

However, the new neoliberal culture has suffered a serious blow from the broad scientific public. Neoclassical and neo-institutional methodological individualism, however, have significantly turned towards respecting culture and constructivist paradigms in the last decade. It has been increasingly insisted on logic of communicative actions, in which valuable and rational entities equally participate, exchanging ideas and forming a shared knowledge, which is a part of institutions generally, and socio-cultural capital particularly. The cognitivecultural turning towards knowledge as the only unlimited resource strongly influences the further development of non-institutional theories, and the significance of socio-cultural capital and institutional structures that surround it are seen in the new light. Will it and to what extent affect the bearers of neoliberal state and economic politics and culture in MNE, SER and B\&H to finally give the necessary priority to knowledge and institutional pluralism - remains to be seen. 


\section{Degradation of higher education}

Only the person can create - this elementary fact is often neglected. It points to the priority role of socio-cultural capital in the development of every society. The influence of socio-cultural factors qualitatively determines the level of institutional and economic development. All human activities are part of the overall social system. The concept of sociocultural capital implicitly contains the category (institution) of the education system, from preschool to high education. It significantly impacts the personality socialization in society and contributes to build socio-cultural capital through the accumulation of various types of knowledge, habits, and skills.

Higher education (universities, colleges, institutes, etc.) aims at creating, transferring, and increasing intellectual and human capital (Radjenovic, 2018), which the staff will use in employing in various companies. It is a primary producer of higher education and scientific research. Therefore, it has enormous significance for the cultural, social, and economic development of each state. In MNE, SER, and B\&H, and in the whole region, theoretical and practical research of this issue and the higher education development impact on the forms of knowledge management and development of socio-cultural capital are not sufficiently represented.

Every transition economy (including the considered) in their aspirations to innovate must accept the imperative need for professionals of various profiles, providing efficiency of their training and retraining in order to increase the general level of knowledge and specialty. Because, they primarily depend on the quality of higher education. Individual benefits from education in general have contributed to the rapid increase in the number of participants in education systems in countries with different levels of development in the 20th century. Research on individual education benefits has led to an understanding of its significance in general, and particularly from the aspect of the market entity costs for education as an investment and socio-cultural capital as an institution. Using econometric analysis, experts have shown that the presence of primary education and vocational education in underdeveloped countries increases individuals' incomes by $10-40 \%$. In addition, education also represents a general economic benefit for society, which is much larger than the accumulation of individual benefits. This synergy effect is achieved thanks to the fact that education creates a rich base for innovation and scientific discoveries, which in the future lead to an accelerated pace of economic growth.

Higher education in modern conditions stands as the leading field, which ensures competitive abilities and advantages of the company, because it directly affects the creation of human and intellectual capital, organizational capital, and the competence of personnel (intellectual workers). A strong academic community creates a positive and proactive climate that attracts domestic and foreign investments. H. Jonson (1974) defined three basic university functions: public good (conditional: socio-cultural capital), research activity, and youth training. D. Bear (1974) analyzes higher education as a company that produces different products, primarily human capital. According to De Grof et al. (1998), the university performs four basic functions: teaching and scientific research, expansion of academic and scientific knowledge, education and research at a high level, and providing expert and specialized services to the wider community (governments and/or the private sector, including the labor market).

In a modern knowledge economy, the creation of knowledge depends on the synergy between academic community, business community, and the government. Each actor must be connected with a certain segment of economy: universities are responsible for creating innovations, companies create a new value, and the government manages interactions (transactions) between actors, preserves social goods and rules (Leydesdorff, 2006). Some 
authors, such as H. Etzkowitz (2002, p. 16), distinguish two extreme models for the configuration of the mentioned dynamic links: the etatist model and the laissez-faire model (conditionally: neoliberal).

It is symptomatic that during the visit of considered countries, Nobel laureate E. Maskin (2017) received a reliable information from the official about the great decline in quality in their higher education (expressed through a very low investments in science - 0.1-0.3\% GDP, a relatively small number of scientific references, inflation of diplomas that are not covered by appropriate knowledge, and increased number of plagiarism), in which improvisation replaces creativity. And then he said: "If you want better results, invest in education".

\section{Results of the survey on the impact of certain groups on socio-cultural capital}

We conducted a survey on a sample of 300 respondents in each of the observed countries in order to determine the perception on the impact of individual social relations on the quality of socio-cultural capital. Respondents had a simple task to answer three questions: a) Did sociocultural capital in the post-socialist transition decrease, stagnate or increase? b) Have the listed socio-cultural capitals (bonding, bridging, and linking) in the post-socialist transition decreased, stagnated or increased? c) Which form of socio-capital in the transition period had the greatest impact on the dynamics of socio-cultural capital?

In the survey, the respondents were acquainted with the essence of the aforementioned forms of socio-cultural capital in the following way (according to Putnam 1995; Woolcock, 2001):

- Bridging social capital refers to particularized trust and communicative solidarity within the family and/or friendship. It implies the unconditional trust and support due to kinship, i.e. close relationship. It has the function to ensure developing new ideas, values and perspectives (we assume that this can be accomplished only in conditions of democracy).

- Bonding social capital refers to generalized trust and normative/mechanical solidarity with the same-minded associates and members of various interest clubs and parties. It has the function of contributing to social adaptation and raising the awareness of social actors (we assume that this can best be achieved under the conditions of belonging to the largest parties or party coalitions).

- Linking social capital refers to institutionalized trust and structural/organic solidarity, which is generated in vertical social relationships with privileged persons in government, professional elites, administration, etc. It has the function to provide individual status guarantees (we assume that this can only be achieved through active roles in the exercise of power and administration, that is, lobbying and log-rolling elites and the nomenclature of power).

Table 1. Respondent's answer to the first question

\begin{tabular}{|l|c|c|c|}
\hline Offered answer & MNE & SRB & B\&H \\
\hline decline & $205 / 68,33 \%$ & $243 / 81 \%$ & $192 / 64 \%$ \\
\hline stagnation & $64 / 21,33 \%$ & $33 / 11 \%$ & $71 / 23,66 \%$ \\
\hline growth & $31 / 10,33 \%$ & $24 / 8 \%$ & $37 / 12,33$ \\
\hline
\end{tabular}


Table 2. Respondent's answer to the second question

\begin{tabular}{|l|c|c|c|}
\hline Offered answer & MNE & SRB & B\&H \\
\hline \multicolumn{4}{|c|}{ Bridging } \\
\hline decline & $29 / 9,66$ & $13 / 43,33 \%$ & $42 / 14 \%$ \\
\hline stagnation & $213 / 71 \%$ & $254 / 84,66 \%$ & $220 / 73,33 \%$ \\
\hline growth & $58 / 19,33 \%$ & $33 / 11 \%$ & $38 / 12,66 \%$ \\
\hline \multicolumn{4}{|c|}{ Bonding } \\
\hline decline & $120 / 40 \%$ & $107 / 35,66 \%$ & $111 / 37 \%$ \\
\hline stagnation & $32 / 10,66 \%$ & $61 / 20,33 \%$ & $92 / 30,66 \%$ \\
\hline growth & $148 / 49,33 \%$ & $132 / 44 \%$ & $97 / 32,33 \%$ \\
\hline \multicolumn{4}{|c|}{ Linking } \\
\hline decline & $49 / 16,33 \%$ & $65 / 21,66 \%$ & $32 / 10,66 \%$ \\
\hline stagnation & $53 / 17,66 \%$ & $48 / 16 \%$ & $63 / 21 \%$ \\
\hline growth & $198 / 66 \%$ & $187 / 62,33 \%$ & $205 / 68,33 \%$ \\
\hline
\end{tabular}

Table 3. Respondent's answer to the third question

\begin{tabular}{|l|c|c|c|}
\hline Offered answer & MNE & SRB & B\&H \\
\hline Bridging & $26 / 8,66 \%$ & $25 / 8,33 \%$ & $32 / 10,66 \%$ \\
\hline Bonding & $63 / 21 \%$ & $76 / 25,33 \%$ & $80 / 26,66 \%$ \\
\hline Linking & $211 / 70,33 \%$ & $197 / 65,66 \%$ & $188 / 62,66 \%$ \\
\hline
\end{tabular}

\section{Results of the survey on the impact of inherited and imposed factors}

In the second (special) survey, the respondents were provided with an orientation list of respective impact factors (Table 4) as an explanation of the methodological division to inherited and imposed factors.

Table 4. Inherited and imposed impact factors on socio-cultural capital

\begin{tabular}{|l|l|}
\multicolumn{1}{|c|}{$\begin{array}{c}\text { Inherited impact factors } \\
\text { on socio-cultural capital }\end{array}$} & \multicolumn{1}{c|}{$\begin{array}{c}\text { Imposed impact factors } \\
\text { on socio-cultural capital }\end{array}$} \\
\hline $\begin{array}{l}\text { - almost total control by privileged } \\
\text { bureaucratic-party nomenclature, }\end{array}$ & $\begin{array}{l}\text { - combat operations, } \\
\text { - fuined socialist institutions, } \\
\text { - cult of personality, }\end{array}$ \\
- intransigence of authorities, & - globalization, geopolitics and \\
- quality of higher education, & geoconomics, \\
- relatively high level of cultural and social & culture, \\
cohesion, & - alternative institutions, \\
- violence, & - an increase in opportunistic behavior, \\
- high level of social security, & - social pathology, \\
- historical memory, & - violence, \\
- recombination of political elites and other & - collapse of the higher education system, \\
& - deficit of the rule of law, \\
& - antagonism of social subsystems and other \\
\hline
\end{tabular}

Due to the limited space, in this paper we used only the respondent's answers to one of the given questions: In your opinion (perception), which impact on the dynamics of sociocultural capital is greater: inherited or imposed? Answers to other questions will be analyzed in 
one of the following articles. The results of the second survey on a sample of 300 respondents in each of the observed countries are shown in Table 5.

Table 5. Respondent's answers to the question about the dominant impact of inherited and imposed factors on the dynamics of socio-cultural capital

\begin{tabular}{|l|c|c|c|}
\hline Offered answer & MNE & SRB & B\&H \\
\hline Inherited factors & $43 / 14 / 34 \%$ & $58 / 19,34 \%$ & $65 / 21,67 \%$ \\
\hline Imminent factors & $257 / 85,66 \%$ & $242 / 80,66 \%$ & $235 / 78,33 \%$ \\
\hline
\end{tabular}

\section{Conclusion}

Regardless of the deficit of the questions asked (in the first survey), which should include and explain the reasons for the existence of certain phenomena that the respondents perceived, the obtained results suggest the following conclusions:

- Respondents in all observed countries have assessed in a large percentage (sufficiently homogeneous) that socio-cultural capital decreased (64-81\%), in a small percentage that it stagnated (11-23.66\%) and in a negligible percentage that it increased (8-12.33\%).

- Respondents in all observed countries have correctly assessed the role and significance of bridging social capital as the dominantly stagnant phenomenon (71-84.66\%). One can only guess why it failed to achieve its basic function, which, in our opinion, is due to an increase in socio-pathological and opportunistic behavior, quasi-neoliberal economic policy and culture, and strong alternative institutions.

- Respondents have differently assessed the impact of bonding social capital, which prevented a valid scientific conclusion. It can only be assumed whether and to what extent their responses may have been motivated by political and/or national affiliation. Bearing in mind that during the transition period, the majority of the population in the observed countries had existential problems, as their living standards dropped drastically, it can be concluded with great insurance that many respondents have based their perception on the aspect of the offered bonding function. In this sense, some have probably opted for the necessary implementation of a social adaptation to crisis conditions (survival), which leads to the growth of bonding capital, and some to the reduced awareness (for example, benefits of belonging to particular political parties), which leads to a reduction in bonding capital.

- Respondents have in the great majority (62.33-68.33\%) estimated that there was an increase in linking social capital, starting primarily from its offered function in the survey. These assessments indicate that most respondents (knowingly or unknowingly, regardless of their participation in the use of privileges) have assessed (recognized) the growing importance of structural/organic solidarity. Consequently, it indirectly recognizes the responsibility of its growth for the decline in socio-cultural capital. It may seem paradoxical, but the survey have objectively confirmed it.

- The previous conclusion was verified by respondent's answers to the third question, which generated the dominant impact of linking capital on the dynamics of socio-cultural capital. Respondent's answers to the third question in a large percentage (over 80\%) correspond with the answers to the second question on the realized dynamics of linking capital. Therefore, this may be the most significant result of the survey conducted.

Despite selecting the answer to only one question in the second survey, it is significant that respondents have dominantly $(78.33-85.66 \%)$ answered that they perceive the greater impact of imposed factors in comparison to inherited factors on the dynamics of socio-cultural capital. This points to the significant imposition of a new culture (neoliberal) and the 
appropriate forms of people's behavior in society. A more detailed analysis goes beyond the scope of this article.

\section{References}

Acemoglu, D. et al. (2003). Institutional Causes, Macroeconomic Simptoms: Volatility, Crises and Growth. Journal of Monetary Economics, 50, 49-123.

Andrushkiv, B., Vovk, Y., Pohaydak, O., \& Fedyshyn, I. (2011). Crisis of relationship in general theory of crisis. Journal of International Studies, 4(1), 18-25.

Appadurai, A. (1996). Modernity at Large: Cultural Dimensions of Globalization. Univ. of Minnesota Press, Minneapolis.

Bear, D. (1974). The university as a multi-product firm, in Effciency in universities: the La Paz Papers, Universityes of Heriot-Vot \& Stenford, Elsevier Scientific Publishing Company.

Becker, G. S. (1991), Human capital. Chicago.

Bourdieu, P. (1972). Esquisse d'une théorie de la pratique, précédé de trois études d'ethnologie kabyle. Librairie Droz, Genève.

Bourdieu, P. (1986). The Forms of Capital, in Handbook of Theory and Research for the Sociology of Education, Ed. J. Richardson. N. Y., Greenwood, 241-258.

Butnaru, G.I., Mironiuc, M., Huian, C., Haller, A. P. (2018). Analysis of Economic Growth in Tourism Under the Impact of Terrorism and of the Waves of Refugees. Amfiteatru Economic, 20 (Special No. 12), 885-904.

Coleman, J.S. (1988). Social Capital in the Creation of Human Capital. The American Journal of Sociology, 94, S95-S120.

De Grof, J., Niv, G. \& Sve, J. (1998). Democracy and governance in higher education. Kluwer Law International, Hag/London.

Delibasic, M. (2015). The Post-socialist Transition Through the Prism of O. Williamson's Insigh. Montenegrin Journal of Economics, 10(1), 13-24.

Delibasic, M. (2016). Hypothetical Matrix for Institutional Modeling of the Basis for Economic Development in the Countries of Southeast Europe. Montenegrin Journal of Economics, 12(2), 147-159. 10.14254/1800-5845.2016/12-1/9

Draskovic, M., Draskovic, V., Bilan, Y., \& Delibasic, M. (2016). Quasi-Neoliberalism as Quasi Institutional Monisms and Causes of the Crisis in Southeastern Europe. Transformations in Business \& Economics, 15(2B), 755-765

Draskovic, M., Jovovic R., Draskovic V., \& Streimikiene D. (2017). Erosion of Socio-Cultural Capital in South Eastern Europe. Sociological Studies, 7, 99-106.

Drachkovich, M.V., Drachkovich, V.D., Bilan, Yu.V. (2017). Social Institutional Factors of Slow-Down: The Case of South-East European Countries Development. Sociological Studies, 4, 107-115.

Draskovic, M, Jovovic, R., Draskovic, V. \& Jovovic, N. (2017). Levels and factors of transitional crisis in Bosnia and Herzegovina, Montenegro, and Serbia. Economics and Sociology, 10(2), 21-32. DOI: 10.14254/2071- 789X.2017/10-2/2

Draskovic, M., Bauk, Streimikiene \& Draskovic, V. (2017). Testing the Level of Alternative Institutions as a Slowdown Factor of Economic Development: the Case of Montenegro. Amfiteatru Economic, 19(45), 477-492.

Draskovic, V. (2018). Clokotrization of tranzition - critical essays, Agharta Science Publishing House, Centre of Sociological Research, Szczecin.

Draskovic, V., Popov, E. \& Peleckis, K.K. (2017). Modelling of Institutional Changes in Transition Countries - the Gap Between the Theory and Practice. Montenegrin Journal of Economics, 13(1) 125-140. 
Etzkowitz, H. (2002). The Triple Helix of University-Industry-Government: Implications for Policy and Evaluation, Working Paper 2002-11, Institutet för studier av utbildning och forskning, Stockholm.

Fukuyama, F. (1992). The End of History? The National Interest, 89, 1-18.

Hodgson, G. (2007). What are institutions? Voprosy ekonomiki, 8, 28-48.

North, D. (1990). Institutions, Institutional Change and Economic Performance, Cambridge University Press, Cambridge.

Jonson, H. G. (1974). The university and the social welfare: a taxonomic exercis, in Efficiency in universities: the La Paz Papers, Universityes Heriot-Vot \& Stenford, Elsevier Scientific Publishing Company.

Lakic, S., Draskovic, M. (2015). Implications of Institutional Dispositions of Neoliberalism. Montenegrin Journal of Economics, 11(2), 113-124.

Leydesdorff, L. (2006). The Knowledge-Based Economy and the Triple Helix Model, in Wilfred Dolfsma \& Luc Soete (eds.). Understanding the Dynamics of a Knowledge Economy, Edward Elgar, Cheltenham, 42-76.

Parsons, T. (1977). Social Systems and the Evolution of Action Theory. The Free Press and Collier Macmillan, New York and London.

Paldam, M. (2000). Social Capital: One or Many? Definition and Measurement. Journal of Economic Surveys, 14(5), 629-653.

Portes, A. (1998). Social capital: Its Origins and Application in Modern Sociology. Annual Review of Sociology, 24, 1-24.

Putnam, R. (1995). Bowling Alone: The Collapse and Revival of American Community. Journal of Democracy, January, 65-78.

Radjenovic, M. (2018). The Quality of Human Resources in Tourism and Hospitality Industry in Montenegro. Transformation in Business \& Economics, 17(2/44), 86-94.

Radovic, D., Bauk, S., Draskovic, M., \& Delibasic, M. (2018). Institutional Violence in the Countries of Southeast Europe. Transformation in Business \& Economics, 17(2/44), 170179.

Sorokin, P.A. (1992). Person. Civilization. Society. Politizdat, Moskow.

Thomas, W.I., \& Thomas D.S. (1928), The Child in America: Behavior Problems and Programs. Knopf, New York.

Vrânceanu, C.A., \& Iorgulescu, C.M. (2016). A Look at Hofstede's Cultural Dimensions in Two Service Sectors from Romania. Amfiteatru Economic, 18(Special Issue No. 10), 875884.

World Bank (1999). What is Social Capital?. Poverty Net. Retrieved from http://www.worldbank.org/poverty/scapital/whatsc.htm

Woolcock, M. (2001). The place of social capital in understanding social and economic outcomes, Isuma: Canadian Journal of Policy Research, 2(1), 11-17.

Yerznkyan, B., Gassner, L., \& Kara, A. (2017). Culture, Institutions and Economic Performance. Montenegrin Journal of Economics, 13(2), 71-80. 